\title{
A INFLUÊNCIA DA PUBLICIDADE NA TRANSIÇÃO NUTRICIONAL: UMA SÍNTESE PARA ENTENDER A OBESIDADE
}

\begin{abstract}
Francielle Lopes Alves
Doutoranda em Serviço Social, Universidade Federal de Santa Catarina,

francialves@hotmail.com

Moara Monteiro Sant'Helena

Mestranda em Enfermagem, Universidade Federal de Santa Catarina, moara15@hotmail.com Mayara Gelsleichter Assistente Social, Universidade Federal de Santa Catarina, mayarapetsso@gmail.com Letícia Possamai Della

Acadêmica do Curso de Serviço Social, Universidade Federal de Santa Catarina, leticia.pdella@gmail.com
\end{abstract}

\section{RESUMO}

A transiçáo nutricional aparece no Brasil com uma singularidade notável: o agravamento simultâneo de duas situaçóes opostas por definição: uma carência nutricional (a anemia) e uma condição típica dos excessos alimentares, a obesidade. Como entender esse antagonismo de natureza e de tendências em um mesmo contexto histórico, em um mesmo espaço geográfico e em uma mesma populaçáo, de forma até independente de sua heterogeneidade socioeconômica (FILHO et al., 2008). Dessa forma, a obesidade vem transitando de forma progressiva, o que implica definir priorida- 
des e estratégias de ação de saúde pública, em especial à prevenção e ao controle das doenças crônicas, reservando lugar de destaque às açóes de educação em alimentação e nutrição e às práticas de atividades físicas que alcancem, de forma eficaz, todas as camadas sociais da população. Neste contexto, será abordado o papel na mídia, que incide não apenas nos fatores diretamente associados à obesidade, mas em todos os âmbitos da sociedade. Este trabalho busca compreender a transição nutricional e as dimensóes sociais da obesidade, enfatizando seus aspectos em adultos, de modo a apresentar as consequências no âmbito da saúde pública, a partir dos determinantes sociais e ponderaçóes que perpassam à integralidade, diante da percepção de vários saberes e práticas que se agregam na produção de conhecimento e de açóes interativas e reflexivas. A obesidade está classificada como uma doença integrante do grupo das doenças crônicas não transmissíveis (DCNT), com interação de fatores etiológicos desconhecidos, registros agravantes da sua repercussão, de modo natural e prolongada, com quadro clínico extenso, contínuo e brando, compreendido por numerosos fatores incidentes, de diferentes graus de incapacidades e com risco de morte (PINHEIRO; FREITAS; CORSO, 2004). Diante disso, será discorrido sobre o assunto com suporte de estudiosos, atentando para o papel desempenhado pela indústria alimentícia nesse processo de reprodução dos moldes na sociedade, o que interfere diretamente nos determinantes sociais do estado entre saúde e doença. Dentre os elementos que levam à esta realidade, há o papel da indústria alimentícia, das redes de comidas rápidas (fast food), da mídia com suas propagandas na televisão que estimulam o paladar, dos filmes que demonstram o consumo expressivo, dos jogos de colecionar biscoitos, da própria programação da televisão que reproduz um padrão de produtos, dos celulares e das redes sociais que desenvolvem uma estratégia que incentivam os moldes repassados, como o hiperconsumo calórico de alimentos, sempre relacionado ao bem-estar, modo este que influência o viver das pessoas e que pode trazer danos à saúde (SICHIERI; SOUZA, 2008). Nesta dinâmica, grande parte dos seres humanos não relaciona os alimentos à necessidade de nutrir o corpo, mas aos padróes estimulados pela indústria e comércio, os quais apresentam alimentos práticos e que proporcionam satisfação rápida; sem, contudo, proporcionarem os nutrientes básicos para uma alimentação sau- 
dável e equilibrada. Nesse sentido, pode-se afirmar que o processo de transição nutricional faz parte das alteraçóes de nutrição e consumo e dos processos de mudanças demográficas e epidemiológicas, além de tanger mudanças econômicas, sociais, demográficas e de perfil de saúde das populaçóes. Simultaneamente, faz-se a inter-relação da desnutrição com a obesidade, que incide não apenas no sistema de saúde nacional, mas em todos os âmbitos e contextos culturais, sociais e econômicos do país, sendo um obstáculo à concretização do potencial humano. A obesidade vem sendo estudada e questionada e, por isso, desvinculada como estética ou desleixo, de fato está sendo priorizada como uma doença crônica, com seus agravantes e seu devido tratamento por profissionais da saúde e pacientes, dando ênfase para a alarmante realidade em que nos encontramos, e com iniciativa de atendimento de forma integral (REPETTO; RIZZOLLI; BONATTO, 2003). Os custos do excesso de peso para os sistemas de saúde são altos e são diretos e indiretos. Os diretos envolvem gastos com o tratamento da obesidade e suas consequências. Entre os indiretos, encontram-se a perda de renda pela redução da produtividade e o absenteísmo, devido à doença ou incapacidade e à perda de renda futura, por causa de mortes prematuras. Esse estudo busca enfatizar a relevância da obesidade para a saúde pública, com interesse social e aplicando investimentos de incentivo à alimentaçáo saudável, incidindo na qualidade de vida de pessoas e favorecendo o tratamento aos que detêm esta doença. Medidas preventivas são consideradas maneiras de combater, e elas podem estar associadas às alteraçóes na estrutura urbana, legislaçóes e subsídios, como incentivos fiscais para produtores de alimentos orgânicos e para empresas que incentivam a prática de atividades físicas dos empregados, além de consultorias nutricionais para refeiçóes escolares e empresariais, entre outras. Está é uma maneira de acesso e de grande chance de ser efetivo o combate preventivo e de tratamento para a obesidade. A materialização de ações que intervenham na alimentação é de extrema importância e deve ser potencializada pela atenção primária à saúde, sendo esse um espaço preeminente ao progresso das açóes de incentivo e apoio ao seguimento de hábitos alimentares saudáveis e à atividade física regular, provocando a reflexão e disseminação da informação sobre os fatores individuais e coletivos que interferem no senso crítico e nas práticas de saúde da sociedade (COUTINHO; GENTIL; TORAL, 2008). 
Palavras-chave: Obesidade; Transição Nutricional; Mídia Audiovisual.

\section{AGRADECIMENTOS}

Às minhas superincentivadoras, exemplos de profissionais e estudiosas do assunto. Vocês são inspiraçôes para mim, Fran, Mô e May.

\section{REFERÊNCIAS}

FILHO, M. B. et al. Anemia e obesidade: um paradoxo da transição nutricional brasileira. Cadernos de Saúde Pública [on-line], v.24, n.2, p.247-257, 2008.

COUTINHO, J. G.; GENTIL, P. C.; TORAL, N. A desnutrição e obesidade no Brasil: o enfrentamento com base na agenda única da nutriçăo. Cadernos de Saúde Pública [on-line], v.24, n.2, p.332-340, 2008.

PINHEIRO, A. R. O.; FREITAS, S. F. T.; CORSO, A. C. T. Uma abordagem epidemiológica da obesidade. Revista de Nutriçáo da PUCCAMP, Campinas, v.17, p.523-533, 2004.

REPETTO, G.; RIZZOLLI, J.; BONATTO, C. Prevalência, riscos e soluções na obesidade e sobrepeso. Arquivos Brasileiros de Endocrinologia e Metabologia [on-line], v.47, n.6, p.633-635, 2003.

SICHIERI, R.; SOUZA, R. A. Estratégias para prevenção da obesidade em crianças e adolescentes. Cadernos de Saúde Pública [on-line], v.24, n.2, p.209-234, 2008. 